\title{
Duodenal Duplication Cysts in Children: Clinical Features and Current Treatment Choices
}

\author{
Valeria Dipasquale ${ }^{a}$ Paolo Barraco ${ }^{a}$ Simona Faraci ${ }^{b}$ Valerio Balassone ${ }^{b}$ \\ Paola De Angelis ${ }^{b} \quad$ Francesco Maria Di Matteo $^{c}$ Luigi Dall'Oglio ${ }^{b}$ \\ Claudio Romano ${ }^{a}$ \\ a Pediatric Gastroenterology and Cystic Fibrosis Unit, Department of Human Pathology \\ in Adulthood and Childhood G. Barresi, University Hospital of Messina, Messina, Italy; \\ b Digestive Endoscopy and Surgery Unit, Children's Hospital Bambino Gesù, Rome, Italy; \\ 'Digestive Endoscopy Unit, Campus Bio-Medico, University of Rome, Rome, Italy
}

\section{What Is It about?}

- We reviewed English-language pediatric reports of duodenal duplication cysts published over the last 20 years. Duodenal duplication cysts are rare gastrointestinal tract malformations occurring during embryonic development. Most patients experience symptoms in the first decade of life. Clinical presentation is variable, depending on the size and location of the cyst and its relationship with nearby structures. Symptoms commonly include recurrent abdominal pain, nausea and vomiting. Pancreatitis is the most frequent complication. Treatment involves complete surgical resection even for asymptomatic patients. Endoscopic marsupialization is a valid conservative treatment, especially if the anatomical relation with the pancreaticobiliary tract is unclear.

\section{Keywords}

Duodenal duplication cyst · Imaging · Endoscopy · Surgery $\cdot$ Pediatrics

\section{Abstract}

Background: Duodenal duplication cysts are rare gastrointestinal tract malformations. Most patients experience symptom onset in the first decade of life. This review aims to examine clinical presentation, management strategies and outcomes of duodenal duplication cysts in childhood. Methods: A Pubmed/Medline (http://www.ncbi.nlm.nih.gov/pubmed/) search in October 2019 for articles published since 1999 using the keywords "duodenal duplication cyst," "child" and "newborn" was carried out. Clinical symptoms, complications, diagnostic examinations, treatment options and outcomes were analyzed and tabulated. Results: There were 41 citations in the literature providing adequate descriptions of 45 cases of duodenal 
duplication cysts. The age of presentation ranged from newborn to 18 years. The median interval between initial presentation and definitive diagnosis and treatment was 17 months (range: 2 months to 12 years). Overall, $67 \%$ of cases presented with abdominal pain, and $43 \%$ were complicated with pancreatitis. Different surgical and endoscopic therapeutic strategies were reported. Conclusions: Duodenal duplication cysts may be associated with life-threatening complications and/or recurrent symptoms, impairing quality of life. Early recognition of patients who demonstrate suggestive signs and symptoms is important to ensure success of treatment. This review may be useful to highlight the main diagnostic aspects and limit the risk of a delayed diagnosis.

\section{Introduction}

Gastrointestinal (GI) tract duplication cysts are rare congenital anomalies that occur during embryonic development, in young patients and adults [1]. Criteria for diagnosis are intimate attachment to the native GI tract, smooth muscle coat and alimentary mucosal lining $[1,2]$. Several theories have been proposed to explain their development, including the split notochord syndrome (commonly used to explain thoracic duplications, probably due to the incomplete separation of the notochord from the GI endoderm), defects in recanalization involving the neonatal solid GI tract and embryonic diverticulum remnants [2, 3]. However, none of these theories alone is able to explain the heterogeneity of these lesions, and to date the cause of GI tract duplication cysts remains debated. The most common location of GI tract duplication cysts is the distal ileum, followed by the esophagus and ileocecal region, while the duodenal duplication cyst is extremely rare and accounts for only $4 \%$ of all GI tract duplications [4]. The estimated prevalence of duodenal duplication cysts is less than 1 per 100,000 live births [5]. A 2010 meta-analysis identified less than 50 published cases of duodenal duplication cysts in both adult and pediatric populations in 10 years [5]. The aim of this review is to report on clinical presentation, management strategies and outcomes of duodenal duplication cysts in children.

\section{Methods}

A Pubmed/Medline (http://www.ncbi.nlm.nih.gov/pubmed/) search in October 2019 for articles published since 1999 using the keywords "duodenal duplication cyst," "child" and "newborn" yielded 68 articles published in English-language journals (Fig. 1). These publications were all reviewed. The reference lists of all retrieved articles were manually reviewed to identify any further relevant studies. Articles that did not have a full text available online were excluded. There were 44 reports [5-49] that provided adequate descriptions of 53 cases of duodenal duplication cysts in children and adolescents (Table 1).

\section{Results}

\section{Demographics and Clinical Presentation}

Of 51 cases with a description of gender, 30 were female. The age of presentation ranged from newborn $[9,19]$ to 18 years [24, 29]. Most patients $(n=42,79 \%)$ experienced symptom onset in the first decade of life. Outcome was described in 27 patients. There were no deaths or cases of relapsing symptoms during follow-up periods ranging from 3 months to 5 years.

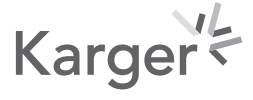


Fig. 1. Flowchart and results of

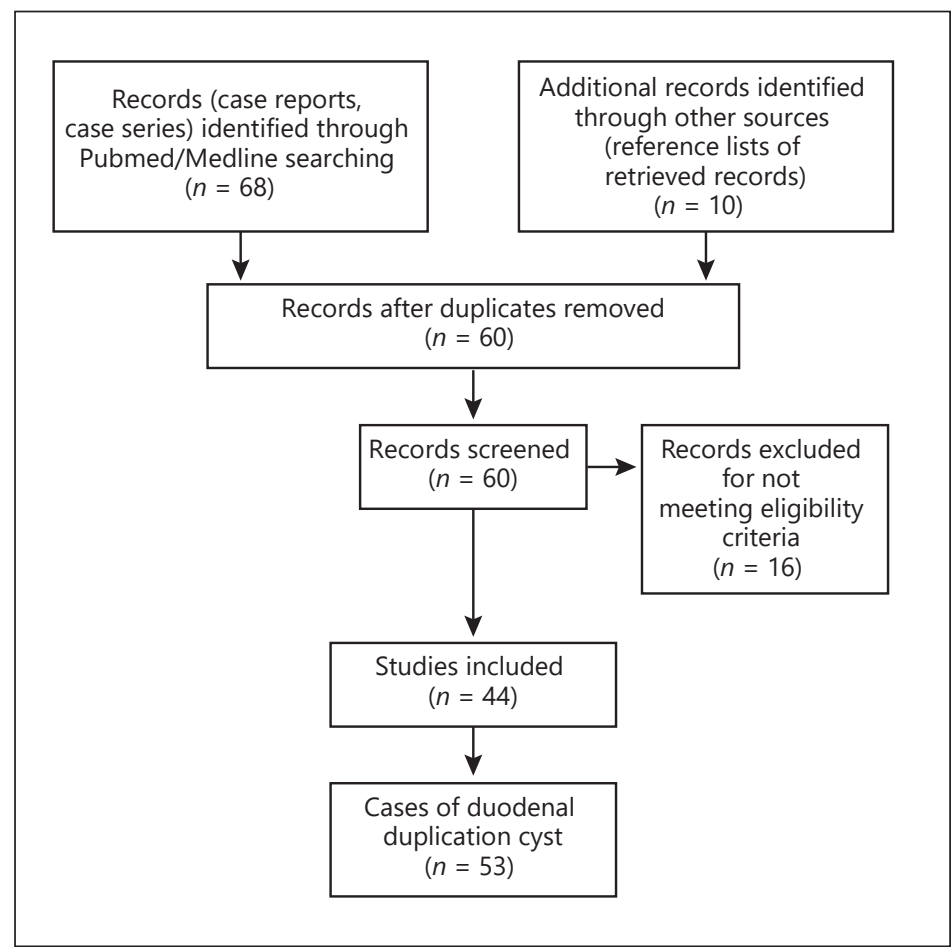
literature review.

The initial presentation of duodenal duplication cyst was variable. The most frequently reported clinical manifestations were abdominal pain $(n=33)$, nausea/vomiting $(n=28)$ and pancreatitis $(n=20)$, either acute $(n=9)$, recurrent $(n=10)$ or chronic $(n=1)$, followed by cholestasis or hepatitis, failure to thrive or weight loss, GI bleeding, fever, cyst infection, gastroesophageal reflux, intussusceptions and stridor. Eight cases had a prenatal diagnosis made after ultrasound (US) [11, 16, 22, 28, 34, 36, 38], whereas one other was asymptomatic and was an incidental finding [24]. The most common complication was pancreatitis, which occurred in $38 \%$ of reported pediatric patients. Hepatobiliary involvement, including hepatitis or cholestasis, was also reported in $13 \%$ of patients.

\section{Characteristics of Duodenal Duplication}

The cyst size varied from $2.0 \mathrm{~cm}$ [38] to giant cysts [34, 35]. In 41 cases, the duodenal duplications were located within the duodenal wall (more commonly in the II portion). In the remaining 12 cases, the location of the duplication was variable. Seven were within the pancreas: 5 in the pancreatic head $[5,14,21,39,44], 1$ in the aberrant lobe connected with the main pancreatic lobe [45] and 1 in the pancreatic tail [37]. In 5 cases, the duplication cysts were not found within the pancreas. Twenty cysts communicated with the lumen of the native duodenum, and 11 were connected to the pancreaticobiliary ducts (common bile duct, main pancreatic duct). A pancreatic pseudocyst was associated with the duodenal duplication cyst in 3 patients [37, 43, 47]. Some cysts were examined and contained stones, bile, thrombi, blood, clear fluid or turbid fluid. No malignant lesions were found inside them.

\section{Diagnostic Tools}

In the reported cases, abdominal US, abdominal computed tomography (CT), magnetic resonance imaging (MRI) and magnetic resonance cholangiopancreatography (MRCP) were the most frequently used diagnostic tools, based on clinical suspicion. Upper GI series and endoscopic retrograde cholangiopancreatography (ERCP) were also performed. The false- 
Biomedicine Hub

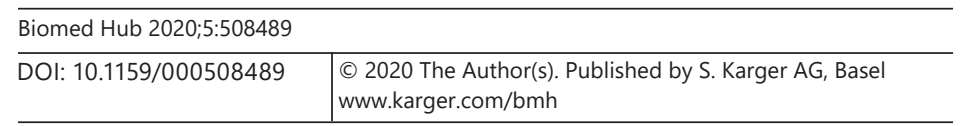

Dipasquale et al.: Duodenal Duplication Cysts in Children

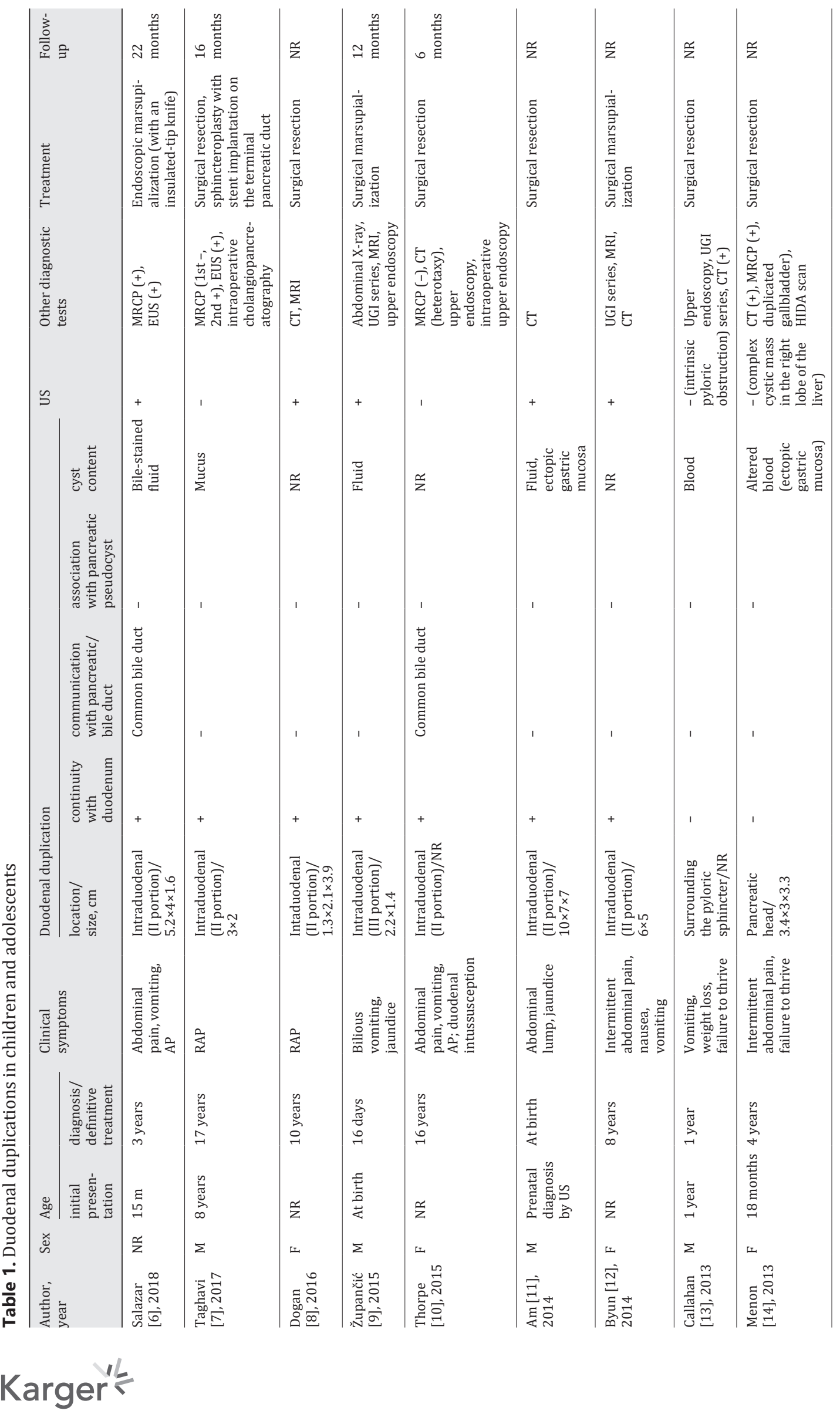


Biomedicine

Hub

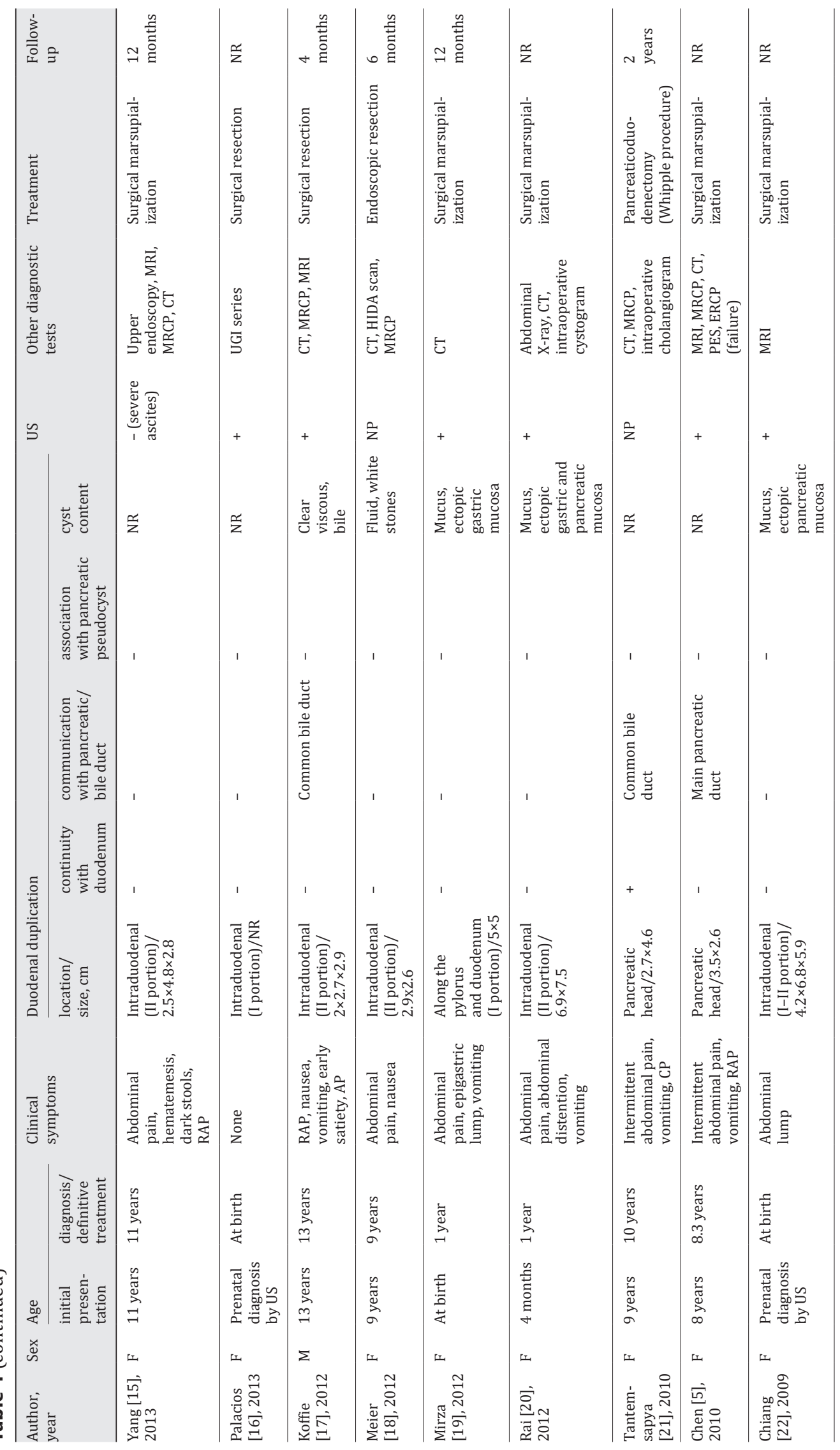


Biomedicine

Hub

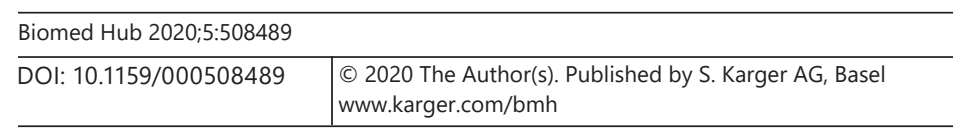

Dipasquale et al.: Duodenal Duplication Cysts in Children

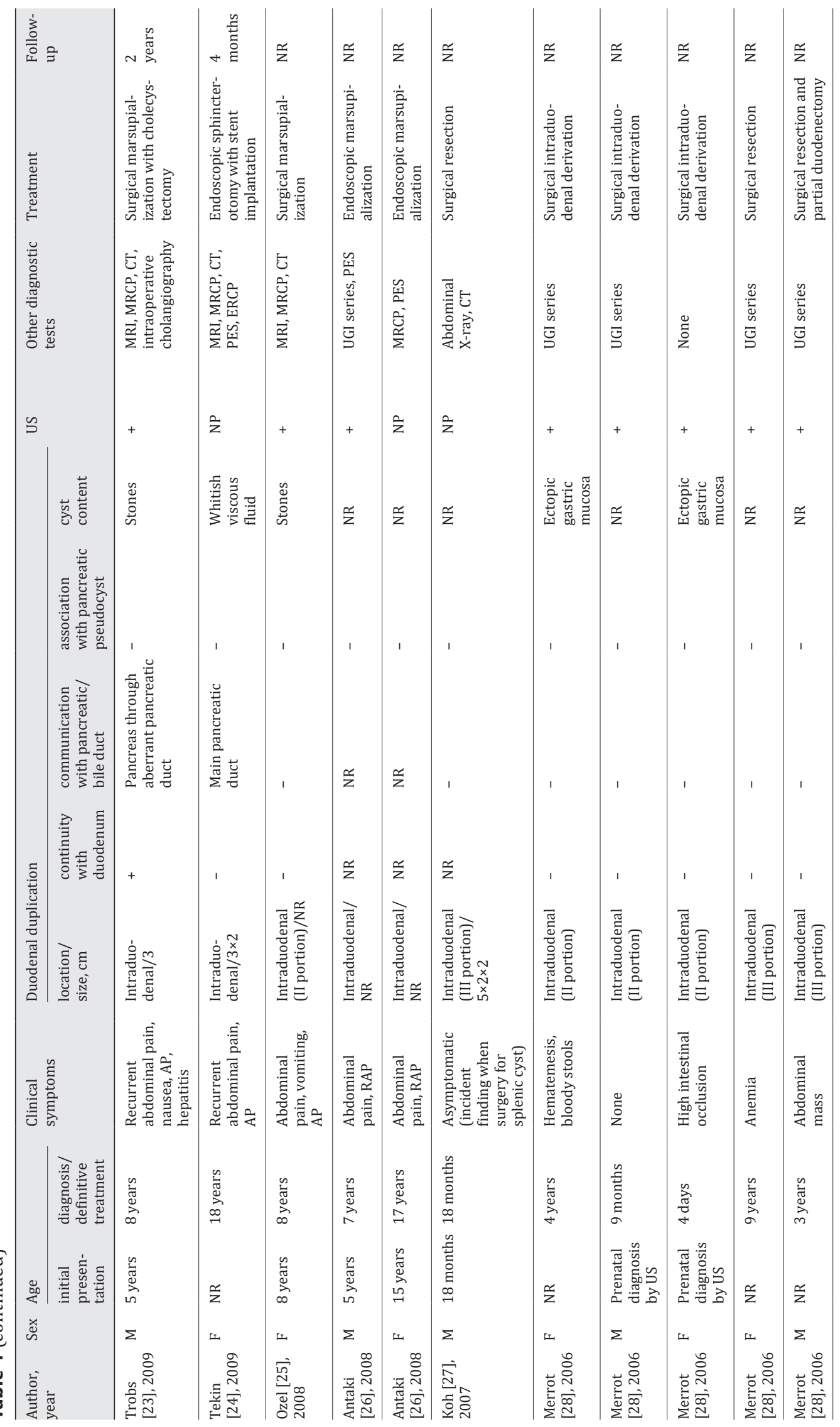


Biomedicine

Hub

\begin{tabular}{l|l}
\hline Biomed Hub 2020;5:508489 \\
\hline DOI: 10.1159/000508489 & $\begin{array}{l}\text { @ 2020 The Author(s). Published by S. Karger AG, Basel } \\
\text { www.karger.com/bmh }\end{array}$ \\
\hline
\end{tabular}

Dipasquale et al.: Duodenal Duplication Cysts in Children

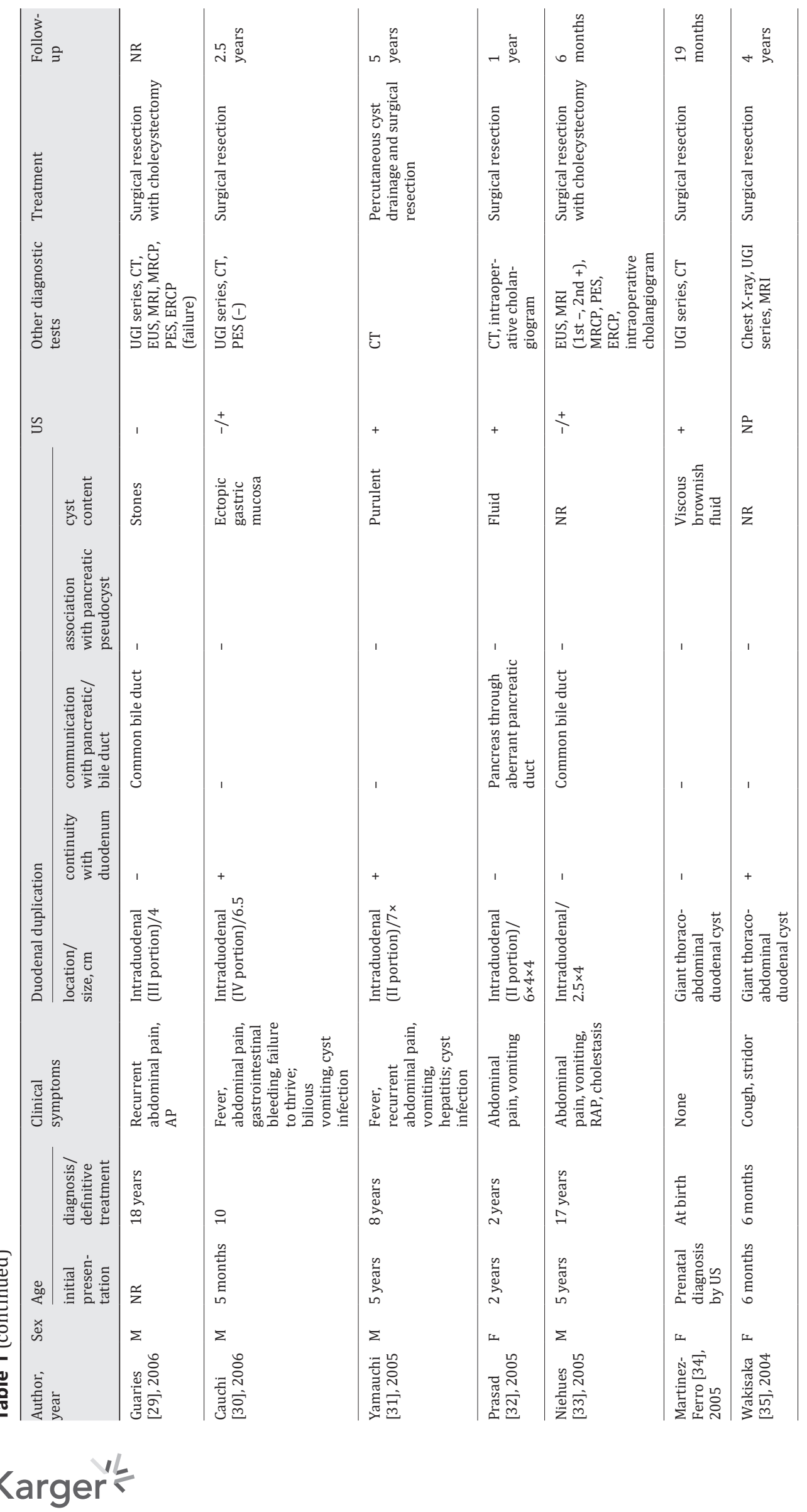


Biomedicine

Hub

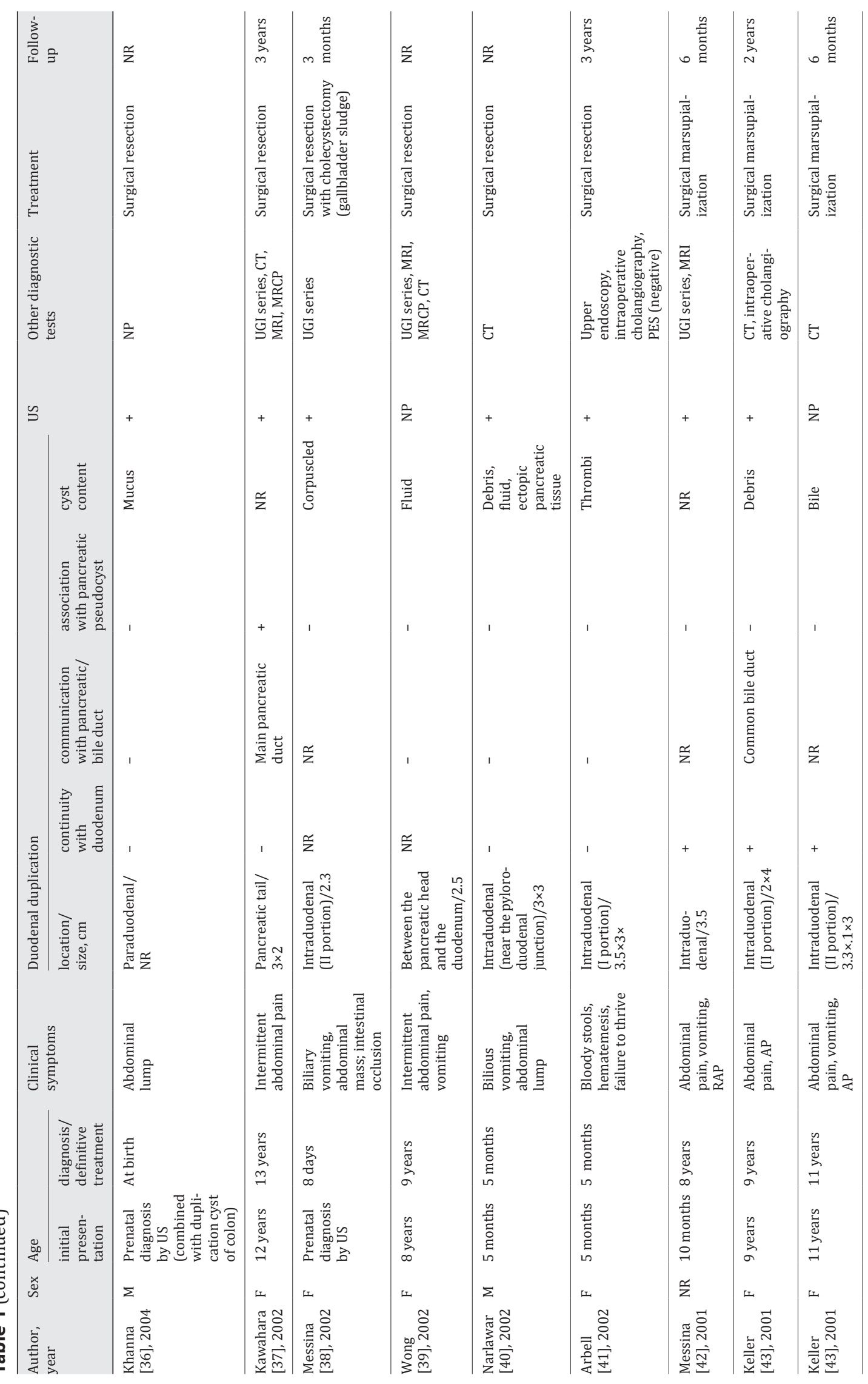

Biomed Hub 2020;5:508489

Dipasquale et al.: Duodenal Duplication Cysts in Children 
Biomedicine

Hub

\begin{tabular}{l|l}
\hline \multicolumn{1}{l}{ Biomed Hub 2020;5:508489 } \\
\hline DOI: 10.1159/000508489 & $\begin{array}{l}\text { (c) 2020 The Author(s). Published by S. Karger AG, Basel } \\
\text { www.karger.com/bmh }\end{array}$ \\
\hline
\end{tabular}

Dipasquale et al.: Duodenal Duplication Cysts in Children

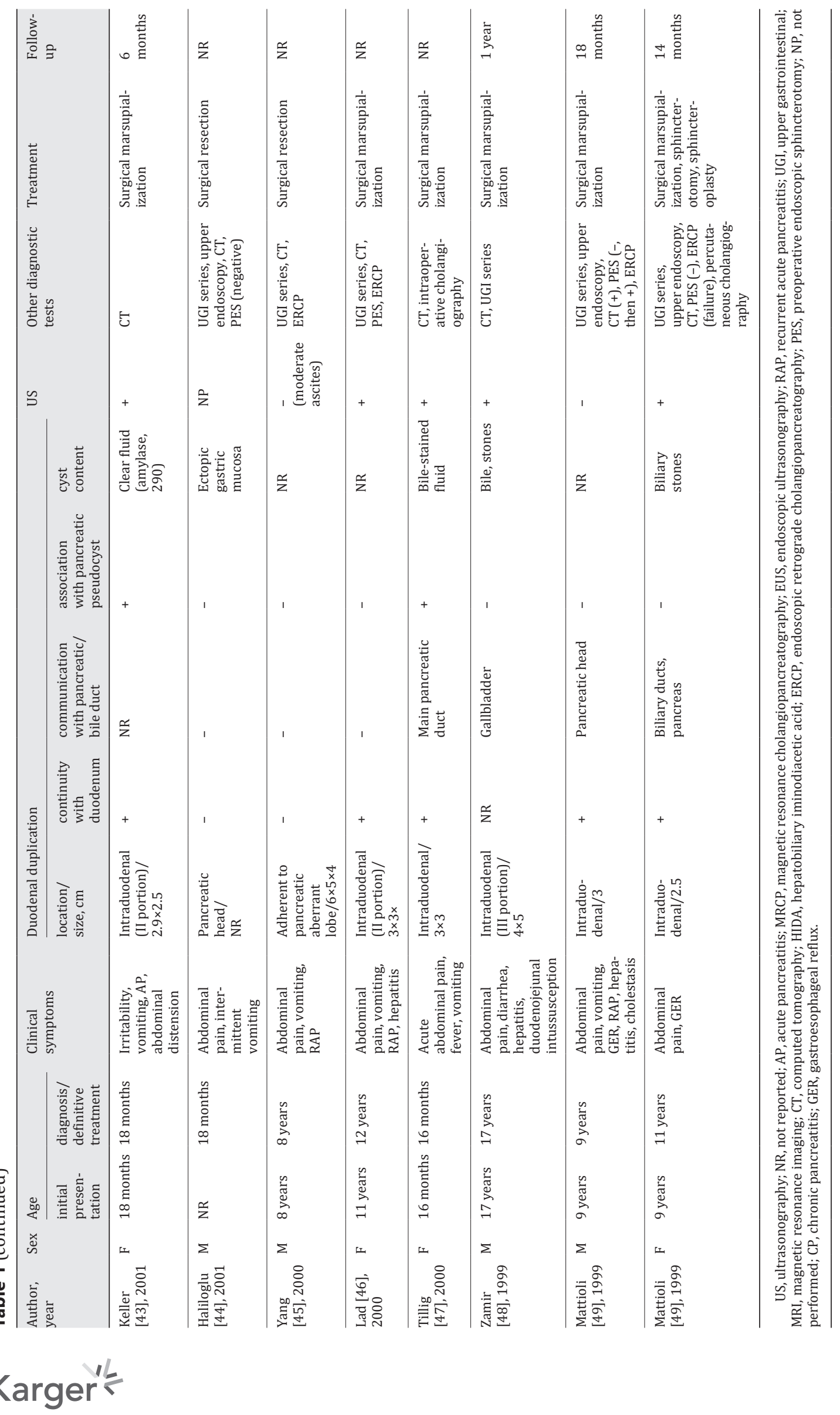


negative rates were $24 \%$ with ultrasound and $5 \%$ with CT scan or MRI/MRCP. The median interval between initial presentation and definitive diagnosis and/or treatment was 17 months (range: 2 months to 12 years). One patient had had other operations before definitive diagnosis [13].

\section{Treatment}

Forty patients underwent surgical treatment of the cyst, including 21 surgical resections, 18 surgical marsupializations, 4 cholecystectomy and 1 pancreaticoduodenectomy. Five patients were successfully treated by endoscopic marsupialization $[6,15,21,23]$. No patients received medical therapy alone.

\section{Discussion}

Duodenal duplication cysts represent a minor part of all GI tract duplications. They were first described by Calder in 1733 [2]. The pathogenic mechanism seems to be related to a duodenal epithelial pinching during the outgrowth of the dorsal pancreatic bud or epithelial sequestration [3]. Clinical presentation of the duodenal duplication cyst is highly variable, depending on the size and location of the cyst and its relationship with nearby anatomical structures. The time interval between the onset of symptoms and the diagnosis is relatively long (median $>1$ year), consisting of diagnostic delay which may be explained by the scarce specificity of symptoms and knowledge of the entity. The most common presenting symptoms include abdominal pain, nausea and vomiting. Pancreatitis is the most frequently reported complication, due to differentmechanisms: (a) transient, mobility-related duodenal obstruction of the major papilla outflow by the cyst; (b) compression of the pancreatic duct or hepatobiliary tree by a large cyst [29]; (c) obstruction of the pancreatic duct by migrating biliary sludge or microstones, viscid mucous secretions or shed cyst blood $[33,38]$. Acute episodes of pancreatitis usually resolve after bowel rest and medical treatment. A high index of suspicion for anatomical etiologies is mandatory in cases of recurrent pancreatitis. In the case of ectopic gastric mucosa (up to $20 \%$ of cases) there could be intracystic hemorrhage or perforation of the cyst with GI bleeding and peritonitis $[14,19,20,44]$. Intraluminal cysts are difficult to differentiate from choledochoceles (type III choledochal cyst) [17, 21]. Differential diagnosis is only possible on pathological examination, since the duodenal duplication cyst is covered both inside and out with duodenal mucosa containing a distinct layer of smooth muscle.

Diagnostic methods include US, MRI or CT, based on clinical suspicion. Two US signs which are highly suggestive of enteric duplication have been described: the presence of peristalsis and the pathognomonic "double-wall" sign, such as an inner hyperechoic rim correlating with the mucosa-submucosa and an outer hypoechoic layer representing the muscularis propria. US is the elective test also for prenatal diagnosis, which allows close neonatal surveillance [16]. Endoscopic US can be useful to assess the cyst, especially if there is biliary obstruction or pancreatitis [50]. Contrast-enhanced CT scans may demonstrate the location and size of the cyst as well as any accompanying lesions of the pancreatic head. An ERCP is useful to outline ductal anatomy and communication to the main pancreatic duct, especially in planning the surgical approach. MRCP is a valid, noninvasive alternative, especially in small children when ERCP is not appropriate [21]. An intraoperative cystogram may be useful to rule out communication of the cyst with biliary and alimentary tracts [20]. Because of its rarity and variety in terms of clinical presentation and radiological findings, preoperative diagnosis is not always correct [13, 25,33].

The choice of the best treatment depends on the size and location of the cyst and its relationship with the nearby anatomical structures. Treatment of duodenal duplication cysts 
classically involves complete surgical resection, either by local excision or by pancreaticoduodenectomy for the cysts that involve the pancreaticobiliary tract. The close proximity of the major papilla and the associated risk of surgical complications stimulated an interest in treating these cases endoscopically [6]. Endoscopic marsupialization using a needle-knife, sphincterotome, or polypectomy snare, is less invasive than a surgical approach and leads to faster recovery times but has only been used in few selected cases, especially cases in which the anatomical relation with the pancreaticobiliary tract is not clear.

Prognosis is excellent if total excision is achieved and there are no histological elements of malignancy. When complete resection is not feasible, the excision of as much as possible of the duplication and mucosal stripping of the rest are recommended, especially to remove ectopic gastric mucosa [20]. Although a very rare occurrence, duodenal duplication cysts may contain dysplasia mucosa or early malignancy tissue. Ma et al. [51] reported 67 cases of malignancies arising from alimentary tract duplication cysts from a 57-year literature review and identified 3 arising from the duodenum in adult patients. Complete surgical resection is the optimal treatment also for asymptomatic patients, to prevent any complication and the risk of dysplastic or malignant lesions [51]. However, timing of resection in asymptomatic patients is still controversial. Some authors suggest early removal (within the first 6 months of life) because of the high rate of complications that can occur in the first year of life, while others conclude that it is safe to wait until the asymptomatic child is older, when elective surgery is technically easier [16].

This review is limited by the small number of studies available in the literature investigating this relatively rare GI malformation in children and adolescents. Furthermore, the studies that were identified and included in this semiquantitative and narrative review are mainly case series and case reports.

In conclusion, duodenal duplication cysts are rare congenital anomalies but can be associated with life-threatening complications and/or recurrent symptoms impairing quality of life of young patients. Lack of specific signs and symptoms makes diagnosis a challenge even for expert clinicians. For repeated abdominal pain in children and adolescents, a duodenal duplication cyst needs to be ruled out. The choice of the best therapeutic technique depends on the size and location of the cyst and its relationship with the nearby anatomical structures. The ideal goal for the management of duodenal duplication cysts should be to diagnose and treat before the onset of pancreatic complications. This review can guide health care providers towards an early diagnosis and the best therapeutic choice.

\section{Disclosure Statement}

The authors have no conflicts of interest to declare. The authors have no financial interests.

\section{Author Contributions}

All 8 authors had full access to all study data and take responsibility for the integrity of the data and the accuracy of the data analysis. Study concept and design: V.D., P.B., S.F., V.B., P.D., F.M.D., L.D., C.R. Acquisition, analysis and interpretation of data: V.D., P.B., S.F., V.B., P.D., F.M.D. Drafting of the manuscript: V.D. Critical revision of the manuscript for important intellectual content: V.D., P.B., S.F., V.B., P.D., F.M.D., L.D., C.R. Study supervision: L.D., C.R.

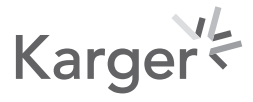




\section{References}

1 Liu R, Adler DG. Duplication cysts: Diagnosis, management, and the role of endoscopic ultrasound. Endosc Ultrasound. 2014 Jul;3(3):152-60.

2 Calder J. Medical essays and observations. Edinburgh: The Royal College of Physicians of Edinburgh; 1733. p. 205.

3 Richer JP, Faure JP, Maillot N, Silvain C, Levillain P, Carretier M. Duodenal duplication cyst communicating with the bile duct with a long common biliary-pancreatic channel. Eur J Surg. 2000 Jun;166(6):504-7.

4 Stringer MD, Spitz L, Abel R, Kiely E, Drake DP, Agrawal M, et al. Management of alimentary tract duplication in children. Br J Surg. 1995 Jan;82(1):74-8.

5 Chen JJ, Lee HC, Yeung CY, Chan WT, Jiang CB, Sheu JC. Meta-analysis: the clinical features of the duodenal duplication cyst. J Pediatr Surg. 2010 Aug;45(8):1598-606.

6 Salazar E, Sin EI, Low Y, Khor CJ. Insulated-tip knife: an alternative method of marsupializing a symptomatic duodenal duplication cyst in a 3-year-old child. VideoGIE. 2018 Sep;3(11):356-7.

7 Taghavi K, Wilms H, Bann S, Stringer MD. Duodenal duplication cyst causing recurrent pancreatitis. J Paediatr Child Health. 2017 Aug;53(8):814-6.

8 Dogan MS, Doganay S, Koc G, Gorkem SB, Ciraci S, Coskun A. Imaging findings of intraluminal duodenal duplication cyst in a pediatric patient. Pediatr Neonatol. 2017 Apr;58(2):194-5.

9 Župančić B, Gliha A, Fuenzalida JV, Višnjić S. Duodenal duplication cyst: a rare differential diagnosis in a neonate with bilious vomiting. European J Pediatr Surg Rep. 2015 Dec;3(2):82-4.

10 Thorpe MA, Nijagal A, Mooney D. Surgical management of an intussuscepted duodenal duplication cyst in a pediatric patient with heterotaxy. J Pediatr Surg Case Rep. 2015;3(10):455-8.

11 Am H, Bm E. Neonatal duodenal duplication cyst. J Neonatal Surg. 2014 Jan;3(1):11.

12 Byun J, Oh HM, Kim SH, Kim HY, Jung SE, Park KW, et al. Laparoscopic partial cystectomy with mucosal stripping of extraluminal duodenal duplication cysts. World J Gastroenterol. 2014 Jan;20(4):1123-6.

13 Callahan K, Lee S, Stewart S, Berkowitz C. Hemorrhagic pyloroduodenal duplication cyst misdiagnosed as child abuse. J Pediatr. 2013 Oct;163(4):1224-1224.e1.

14 Menon P, Rao KL, Thapa BR, Goyal R, Garge S, Rathore MK, et al. Duplicated gall bladder with duodenal duplication cyst. J Pediatr Surg. 2013 Apr;48(4):e25-8.

15 Yang M, Li DY, Zeng YM, Chen PY, Geng LL, Gong ST. Recurrent acute pancreatitis and massive hemorrhagic ascites secondary to a duodenal duplication in a child: a case report. J Med Case Reports. 2013 Mar;7(1):70.

16 Palacios A, De Vera M, Martínez-Escoriza JC. Prenatal sonographic findings of duodenal duplication: case report. J Clin Ultrasound. 2013 Nov-Dec;41 Suppl 1:1-5.

17 Koffie RM, Lee S, Perez-Atayde A, Mooney DP. Periampullary duodenal duplication cyst masquerading as a choledochocele. Pediatr Surg Int. 2012 Oct;28(10):1035-9.

18 Meier AH, Mellinger JD. Endoscopic management of a duodenal duplication cyst. J Pediatr Surg. 2012 Nov; 47(11):e33-5.

19 Mirza B. Pyloroduodenal duplication cyst: the rarest alimentary tract duplication. APSP J Case Rep. 2012 Sep; 3(3):19.

20 Rai BK, Zaman S, Mirza B, Hanif G, Sheikh A. Duodenal duplication cyst having ectopic gastric and pancreatic tissues. APSP J Case Rep. 2012 May;3(2):15.

21 Tantemsapya N, Chin A, Melin-Aldana H, Superina RA. Intrapancreatic duodenal duplication cyst as a cause of chronic pancreatitis in a child. Eur J Pediatr Surg. 2010 Mar;20(2):125-8.

22 Chiang LL, Hsieh WH, Shih JC, Hsu WM. Treatment of duodenal duplication by trans-umbilical exploratory minimal laparotomy. Pediatr Neonatol. 2009 Aug;50(4):169-72.

23 Tröbs RB, Hemminghaus M, Cernaianu G, Liermann D. Stone-containing periampullary duodenal duplication cyst with aberrant pancreatic duct. J Pediatr Surg. 2009 Jan;44(1):e33-5.

24 Tekin F, Ozutemiz O, Ersoz G, Tekesin O. A new endoscopic treatment method for a symptomatic duodenal duplication cyst. Endoscopy. 2009;41(S 02 Suppl 2):E32-3.

25 Ozel A, Uysal E, Tufaner O, Erturk SM, Yalcin M, Basak M. Duodenal duplication cyst: a rare cause of acute pancreatitis in children. J Clin Ultrasound. 2008 Nov-Dec;36(9):584-6.

26 Antaki F, Tringali A, Deprez P, Kwan V, Costamagna G, Le Moine O, et al. A case series of symptomatic intraluminal duodenal duplication cysts: presentation, endoscopic therapy, and long-term outcome (with video). Gastrointest Endosc. 2008 Jan;67(1):163-8.

27 Koh CC, Wang NL, Lee HC, Duh YC. Infected congenital splenic cyst associated with duodenal duplication cyst and malrotation-a case report. J Pediatr Surg. 2007 Dec;42(12):e21-2.

28 Merrot T, Anastasescu R, Pankevych T, Tercier S, Garcia S, Alessandrini P, et al. Duodenal duplications. Clinical characteristics, embryological hypotheses, histological findings, treatment. Eur J Pediatr Surg. 2006 Feb; 16(1):18-23.

29 Guarise A, Faccioli N, Ferrari M, Romano L, Parisi A, Falconi M. Duodenal duplication cyst causing severe pancreatitis: imaging findings and pathological correlation. World J Gastroenterol. 2006 Mar;12(10):1630-3.

30 Cauchi JA, Buick RG. Duodenal duplication cyst: beware of the lesser sac collection. Pediatr Surg Int. 2006 May; 22(5):456-8.

31 Yamauchi Y, Hoshino S, Yamashita Y, Funamoto S, Ishida K, Shirakusa T. Successful resection of an infected duodenal duplication cyst after percutaneous cyst drainage: report of a case. Surg Today. 2005;35(7):586-9. 
32 Prasad TR, Tan CE. Duodenal duplication cyst communicating with an aberrant pancreatic duct. Pediatr Surg Int. 2005 Apr;21(4):320-2.

33 Niehues R, Dietl KH, Bettendorf O, Domschke W, Pohle T. Duodenal duplication cyst mimicking pancreatic cyst in a patient with pancreatitis. Gastrointest Endosc. 2005 Jul;62(1):190-2.

34 Martinez-Ferro M, Laje P, Piaggio L. Combined thoraco-laparoscopy for trans-diaphragmatic thoracoabdominal enteric duplications. J Pediatr Surg. 2005 Sep;40(9):e37-40.

35 Wakisaka M, Nakada K, Kitagawa H, Shimada H, Nosaka S. Giant transdiaphragmatic duodenal duplication with an intraspinal neurenteric cyst as part of the split notochord syndrome: report of a case. Surg Today. 2004;34(5):459-62.

36 Khanna PC, Gawand V, Nawale AJ, Deshmukh T, Merchant SA. Complete large bowel duplication with paraduodenal cyst: prenatal sonographic features. Prenat Diagn. 2004 Apr;24(4):312-4.

37 Kawahara H, Takahashi T, Okada A. Characteristics of duodenal duplications causing pancreatitis in children and adolescents: a case report and review of the literature. J Pediatr Gastroenterol Nutr. 2002 Sep;35(3): 372-6.

38 Messina M, Ferrucci E, Meucci D, Buonocore G, Di Maggio G. Neonatal intestinal occlusion due to duodenal duplication in association with malformed gallbladder sludge. Biol Neonate. 2002;81(3):210-2.

39 Wong AM, Wong HF, Cheung YC, Wan YL, Ng KK, Kong MS. Duodenal duplication cyst: MRI features and the role of MR cholangiopancreatography in diagnosis. Pediatr Radiol. 2002 Feb;32(2):124-5.

40 Narlawar RS, Rao JR, Karmarkar SJ, Gupta A, Hira P. Sonographic findings in a duodenal duplication cyst. J Clin Ultrasound. 2002 Nov-Dec;30(9):566-8.

41 Arbell D, Lebenthal A, Blashar A, Shmushkevich A, Gross E. Duplication cyst of the duodenum as an unusual cause of massive gastrointestinal bleeding in an infant. J Pediatr Surg. 2002 May;37(5):E8.

42 Messina M, Zingaro P, Tiribocchi A, Meucci D, Ferrucci E. Relapsing acute pancreatitis due to duodenal duplication in an 8-year-old child. Case report. Minerva Chir. 2001 Jun;56(3):317-9.

43 Keller MS, Weber TR, Sotelo-Avila C, Brink DS, Luisiri A. Duodenal duplication cysts: A rare cause of acute pancreatitis in children. Surgery. 2001 Jul;130(1):112-5.

44 Haliloglu M, Oto A, Karnak I, Tanyel FC, Eryilmaz M. Intrapancreatic duodenal duplication cyst with inversion of the superior mesenteric vessels: CT findings. Pediatr Radiol. 2001 Mar;31(3):187-8.

45 Yang AD, Chang $\mathrm{CH}$, Wang YM, Lin JC. Relapsing pancreatitis in a child duplication in an aberrant pancreatic lobe. Pediatr Surg Int. 2000;16(7):517-8.

46 Lad RJ, Fitzgerald P, Jacobson K. An unusual cause of recurrent pancreatitis: duodenal duplication cyst. Can J Gastroenterol. 2000 Apr;14(4):341-5.

47 Tillig B, Andreo-Carcia P, Lawrenz K, Engert J. A pancreatic pseudocyst with acute hemorrhage in a childsecondary to a spherical duodenal duplication? A case report. Eur J Pediatr Surg. 2000 Jun;10(3):201-3.

48 Zamir G, Gross E, Shmushkevich A, Bar-Ziv J, Durst AL, Jurim O. Duodenal duplication cyst manifested by duodeno-jejunal intussusception and hyperbilirubinemia. J Pediatr Surg. 1999 Aug;34(8):1297-9.

49 Mattioli G, Buffa P, Pesce F, Barabino A, Ganduglia P, Fratino G, et al. Pancreatitis caused by duodenal duplication. J Pediatr Surg. 1999 Apr;34(4):645-8.

50 Romeo E, Torroni F, Foschia F, De Angelis P, Caldaro T, Santi MR, et al. Surgery or endoscopy to treat duodenal duplications in children. J Pediatr Surg. 2011 May;46(5):874-8.

$51 \mathrm{Ma} \mathrm{H}, \mathrm{Xiao} \mathrm{W}$, Li J, Li Y. Clinical and pathological analysis of malignancies arising from alimentary tract duplications. Surg Oncol. 2012 Dec;21(4):324-30. 